\title{
Convergence versus divergence: care relations across three societies
}

\begin{abstract}
This chapter focused on ways to contribute to better caring societies in Southeast Asia while at the same time advancing their economies. The focus of this chapter is limited to three Southeast Asian countries, which were purposively selected as case studies of societies experiencing rapid demographic and socio-economic transitions. They were the Federation of Malaysia, the Kingdom of Thailand, and the Socialist Republic of Vietnam. The discussion was divided into three sections: looking back, looking forward, and policy recommendations for moving forward. Based on the current and future trends of demographic change, it was clear that Thailand, Vietnam and Malaysia were facing challenges to sustain their economic and social development. The chapter argued that an on-going increase in the proportion and number of the elderly could serve as a hindrance against their prospect to advance their economy on a sustained basis, unless a 2 nd demographic dividend is procured, or there is a strong commitment to increase capital accumulation and investment. This chapter opined that the well-being of a society starts at the individual level and that care should be regarded as a social investment. The chapter offered policy measures for future old-age financial security besides those to minimize impacts on the family.
\end{abstract}

